\title{
Relationship Between Measles Outbreaks Based on Genetic Analysis of Measles Virus Genomes Detected in Patients in Poland Between 2006 and 2012
}

\author{
AGATA MAKÓWKA and BOGUMIŁA LITWIŃSKA \\ National Institute of Public Health-National Institute of Hygiene, Department of Virology, Warsaw, Poland
}

Submitted 5 May 2014; Revised 10 September 2014, Accepted 24 October 2014

\begin{abstract}
This study describes the molecular characterization of $56 \mathrm{MeV}$ strains obtained from 56 patients in Poland from 2006 to 2012 . The C-terminal fragment of nucleoprotein gene was analysed. It has been found out during 2006 and $20012 \mathrm{MeV}$ strains circulating in Poland belonged to genotypes D4, D5, D6 and B3. The D4 strains isolated in Poland were different from any other D4 strain circulating at the same time in Europe, whereas all other MeV strains isolated during 2007-2012 were related to strains from other countries. The present data suggest that after 2006 the $\mathrm{MeV}$ strains were imported.
\end{abstract}

Ke y w ords: measles outbreaks in Poland, genetic analysis of MeV, phylogenetic relationship between $\mathrm{MeV}$ strains

The measles virus $(\mathrm{MeV})$ belongs to the family Paramyxoviridae, sub-family Paramyxovirinae, genus Morbilivirus. The genome of $\mathrm{MeV}$ is a single stranded, negative-sense RNA. Measles is highly infectious disease, characterized by unspecific prodromal symptoms, Koplik's spots and maculopapular rash and fever (Delpuet et al., 2012).

$\mathrm{MeV}$ is serologically monotypic, there is no difference in the reactivity of sera in the course of infection with various $\mathrm{MeV}$. Therefore current vaccines against measles provide protection against all wild-type viruses. However, there are some differences in nucleotide sequences between the $\mathrm{MeV}$ strains (Kühne etal., 2006). The differences within certain genes determine the diversity of $\mathrm{MeV}$ genotypes. On the basis of the sequence of $\mathrm{C}$-terminal fragment of nucleoprotein gene $\mathrm{MeV}$ strains are divided into clades $\mathrm{A}-\mathrm{H}$ and 21 genotypes (WHO, 2012a).

Phylogenetic analysis of wild measles virus strains $(\mathrm{MeV})$ together with epidemiological information, allows identifying sources of infection and distinguishing measles outbreaks between caused by native strains and caused by imported strains from other countries (Shakya etal., 2012). Implementation of such research helps to prove the progress of the measles elimination program.

In 2010 WHO adopted the goal to eliminate endemic measles in the European Region by 2015 (Steffens et al.,
2010). Poland is a member of the WHO and the measles elimination program has been realized for many years. An improvement of the epidemiological situation of measles in Poland has been observed in recent years, due to maintenance of high immunization coverage. Before the introduction in 1974 of immunization against measles in Poland the incidence rate was $300-400$ per 100.000 . After the introduction of vaccination the incidence of measles rapidly decreased to 0,18 per 100.000 in 2012 (Janaszek et al., 2002). At present, vaccination coverage against measles is more than $95 \%$.

Poland is approaching measles elimination. According to the definition, elimination is when endemic measles cases are absent in a given area for at least 36 months from the last known case. A number measles cases were reported in Poland during the last few years, but mainly due to measles importation by travelling people.

The objective of this study was genotyping and phylogenetic analysis of measles virus strains in Poland during 2006-2012, which allows obtaining information about the sources of wild strains of MeV.

The epidemiological information about measles cases during 2006-2012 in Poland (e.g. time of onset, vaccination status, past journeys) was collected by the Department of Epidemiology, National Institute of Public Health-National Institute of Hygiene, Warsaw.

In Poland 120 measles cases were reported in 2006, 37 in 2007, 97 in 2008, 115 cases in 2009, 13 in 2010, 38

\footnotetext{
* Corresponding author: A. Makówka, National Institute of Public Health-National Institute of Hygiene, Departament of Virology, Warsaw, Poland; e-mail: amakowka@pzh.gov.pl
} 
in 2011 and 70 in 2012. They were recorded taking into account the presence of specific IgM antibodies against $\mathrm{MeV}$ and epidemiological link to confirmed measles cases. Among the 56 examined patients, 25 (44,6\%) $\mathrm{MeV}$ strains were derived from Roma people.

According to the epidemiological investigation, 1 measles case in 2006 was associated with the MeV strain imported from Russia, whereas measles cases in 2007 were associated with importation from Ukraine. Measles cases in the Roma community were caused by $\mathrm{MeV}$ strains imported from the UK (2008 and 2009) and Romania (2012). One case in 2012 was a Polish soldier, who returned from the military mission in Libya.

In 2006 measles cases were dispersed in various locations in Poland and there were only a few cases in individual foci, in contrast to other years, when measles cases formed distinct clusters.

A total of 343 clinical samples (blood-105, throat swabs-133, urine-104 and nose swab-1) were collected in Poland during 2006 and 2012 from measles suspected cases were examined. All these samples were obtained from cases reported to the WHO Measles Elimination Programme, according to WHO criteria (WHO, 2012b). The samples were sent to the Department of Virology at National Institute of Public Health-National Institute of Hygiene, Warsaw, which is the National Laboratory for Measles and Rubella in Poland within the Global Measles and Rubella Laboratory Network, WHO.

$\mathrm{MeV}$ RNA was extracted from the clinical samples using QIAamp Viral RNA Mini kit (Qiagen). For detection of viral RNA conservative fragment of nucleoprotein gene of $400 \mathrm{bp}$ corresponding to positions $465-864$ was amplified by the nested RT-PCR method (Tischer etal., 2004). Measles virus RNA was detected in 159 samples collected from 78 patients and then 56 of them was used for sequencing and phylogenetic analysis.

The variable fragment of nucleoprotein gene was amplified and the sequencing was performed by using the internal primers in the second round of amplification. This method has been previously described by Santibanez et.al (Santibanez et al., 2002). The nucleotide sequences of the viral cDNA were analyzed by Chromas (version 1.45). Sequences were aligned and analysed by CLC Sequence Viewer 6.5.3 software. Phylogenetic trees were constructed by means of the neighbour-joining method. Genotype assignment was carried by program NCBI Genotyping Tool available on the website NCBI, USA (Rozanov et al., 2004). This program allows to compare the query sequence with the sequences of $\mathrm{WHO} \mathrm{MeV}$ reference strains and other known $\mathrm{MeV}$ sequences, available in the PubMed database.

Among 78 confirmed by RT-PCR measles cases, only for 56 patients the genotyping and phylogenetic analysis of $\mathrm{MeV}$ strains were possible to complete.
Confirmation of the presence of $\mathrm{MeV}$ RNA in clinical specimens allowed carrying out the sequencing and phylogenetic analysis. The phylogenetic tree illustrates the relationship between $\mathrm{MeV}$ strains isolated in Poland and in other countries. It also includes WHO reference strains (Fig. 1).

Individual clades are formed by the $\mathrm{MeV}$ strains registered in Measles Nucleotide Surveillance, named according to $\mathrm{WHO}$ nomenclature and the $\mathrm{MeV}$ strains closely related to them that were not registered in any database. They were named by laboratory code number. The reference strains are named according to WHO nomenclature.

Genotyping revealed that $\mathrm{MeV}$ strains circulating in Poland between 2006 and 20012 belonged to genotypes D4 (49), D5 (1), D6 (5) and B3 (1). The presented results show that in 2006 the diversity of $\mathrm{MeV}$ genotypes was observed (D4 and D5) whereas in 2007 the genotype of $\mathrm{MeV}$ strains was homogenous (D6). $\mathrm{MeV}$ strains circulated in Poland during 2008 and 2012 were related to each other and belonged to genotype D4.

Endemic transmission of $\mathrm{MeV}$ is defined as a chain transmission that is continuous for more than 12 months in a given area. Imported $\mathrm{MeV}$ strains have virological and epidemiological links with strains from other countries.

Epidemiological data suggests that in 2006 measles cases were caused by an indigenous virus strain circulating in Poland, genotyped D4. These measles cases were not linked to any other D4 strains circulated at the same time. According to the studies carried out in collaboration with Robert Koch Institute in Berlin, $\mathrm{MeV}$ strains isolated in 2006 in Poland were different from other MeV D4 circulating at the same time in Europe and they were related to the $\mathrm{MeV}$ strains detected in 1998 in Australia (MVi/Vic.AUS/10.98 information from WHO Measles/Rubella European Regional Reference Laboratory). In 2006 the genotype D4 was also observed in Romania, however the Polish strains (e.g. MVi/Warsaw.POL/28.06/) were not identical to the Romanian one (MVi/Bucharest. ROU/04.06/3) (Makówka, 2007). The results of these studies suggest that genotype D4 detected in Poland in 2006 was indigenous. This confirms the epidemiological data concerning the size dispersion and number of measles cases in particular foci in Poland in 2006. $\mathrm{MeV}$ strains belonging to genotype $\mathrm{D} 4$ were circulating during 2006 in many European countries (Kremer et al., 2008).

In 2006 one person (MVs/Warsaw.POL/41.06) was infected with genotype D5 of MeV. Sequencing results confirmed that the strain of this case was identical with the strain detected in Russia (MVs/NizhnyNovogrod. RUS/16.07/) and was related to the strain circulating in Germany in 2007 (MVs/Hanover.DEU/21.07/). This 


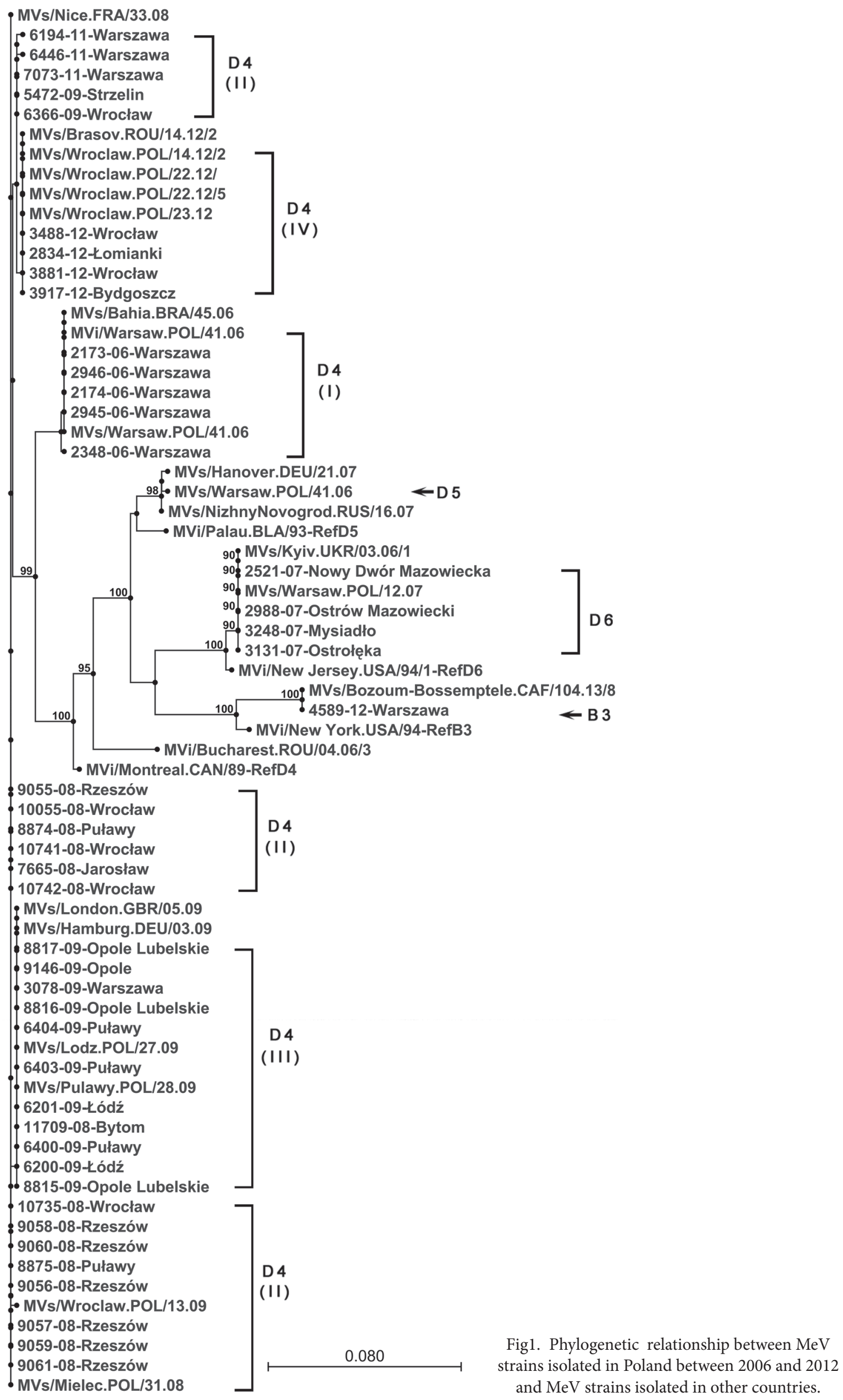


confirmed the epidemiological investigation, which revealed that this sequence was isolated from a person who was diagnosed with measles just after returning from Russia.

In 2007 the genotype D4 in Poland was replaced by genotype D6. The phylogenetic analysis indicates the relationship with MeV strains D6 detected in 20052006 in Ukraine (MVs/Kyiv.UKR/03.06/1), which was also confirmed by the epidemiological investigation. Therefore we conclude that measles in Poland in 2007 was imported from Ukraine (Spika et al., 2006).

$\mathrm{MeV}$ strains isolated in 2008, 2009, 2011 and 2012 in Poland belonged to the genotype D4, however they differ from the strains detected in 2006. This suggests that there was a different source of $\mathrm{MeV}$ strains and a new transmission chain than in 2006. The phylogenetic analysis in this study indicates that $\mathrm{MeV}$ D4 strains, circulating in Poland in these years, were imported from other European countries: France (2008), Germany and Great Britain (2009) and Romania (2012).

The measles outbreaks in Poland in 2008, 2009 and 2012 were mainly observed in the Roma ethnic group. The $\mathrm{MeV}$ strain from 2008 is related to the strain from France (MVs/Nice.FRA/33.08). The MeV strains circulated in 2009 were similar to the D4Hamburg strain (MVs/Hamburg.DEU/03.09/) and to the strain from Great Britain (MVs/London.GBR/05.09/). The MeV strain detected in 2012 was identical to the Romanian one (MVs/Brasov.ROU/14.12/2).

The studies carried out with collaboration with the Robert Koch Institute in Berlin confirmed the results of the phylogenetic analyses. In clinical samples collected in 2009 from Polish patients the MeV strains identical to the D4-Hamburg strain were detected. There were strains isolated from the patients of Roma origin in Łódź, Puławy and Opole Lubelskie (Rogalska et al., 2010; Mankertz et al., 2011).

D4-Hamburg strain was imported from Great Britain to Germany at the end of the year 2008 and then to Bulgaria and caused more than 24 thousand measles cases (Marinowa et al., 2009). It was the largest measles epidemic in Europe since the outbreak in Ukraine in 2006 (Velicko et al., 2008). Furthermore, D4-Hamburg caused many measles causes lasting from 2008 to 2011 e.g. in Ireland, Austria, Greece, Serbia, Macedonia (Melidou et al., 2011). Sporadic measles cases were also observed in Romania, Turkey, Switzerland and they were associated with Roma travellers from Bulgaria (Marinova et al., 2009; Mankertz et al., 2011; Muscat, 2011). Also in the Roma community in Romania some measles cases had been observed in 2004. There were more than 9 thousand measles cases registered and the circulation of D4-Bucharest strain till 2007 was the result of the travelling of Roma people (Kremer et al.,
2008). The strains D4-Bucharest and D4-Hamburg differ from each other, indicating two separate chains of $\mathrm{MeV}$ infection in the Roma population.

The measles outbreak occurred in the Roma community in Poland in 2012 was initiated by a child who had acquired measles in Romania. $\mathrm{MeV}$ strains belonging to genotype D4 were detected in Poland and this variant was found in Romania a few weeks before the beginning of outbreak in Poland (Necula et al., 2013).

In 2012 one sequence belonging to genotype B3 (case 4589-12-Warszawa) was found in a sample derived from a soldier diagnosed with measles just after returning from Lybia and it was identical to the strain isolated in Central African Republic (MVs/BozoumBossemptele.CAF/104.13/8) (Fig. 1). Genotype B3 is frequently associated with measles imported from Africa to many European countries (Riddell et al., 2005).

The results of genetic analysis shows that measles in Poland in 2006 was indigenous, whereas since 2007 measles in Poland was a result of the importation of $\mathrm{MeV}$ strains from other European countries. Between 2006 and 2012 there were 4 various MeV genotypes identified in Poland. In areas, where the indigenous $\mathrm{MeV}$ strains circulation is interrupted, the occurrence of diverse genotypes is observed, indicating different sources of importation of measles. In contrast, in endemic areas a limited number of $\mathrm{MeV}$ genotypes are detected.

The present results show that genotyping and phylogenetic analysis of $\mathrm{MeV}$ is an useful tool for outbreak investigation and Poland is on the right way to measles elimination. It is essential to continue the molecular surveillance of measles in Poland to monitor the pattern transmission of $\mathrm{MeV}$.

\section{Acknowledgements \\ This work was partially supported by Ministry of Science and Higher Education, Poland (NN 4041139 39).}

\section{Literature}

Delpeut S., R.S. Noyce, R.W. Siu and C.D. Richardson. 2012. Host factors and measles virus replication. Current Opinion in Virology 2: 773-783.

Janaszek W., W. Gut and N.J. Gay. 2002. Measles vaccine efficacy during an epidemic in 1998 in the highly vaccinated population of Poland. Vaccine 3446: 1-6.

Kühne M., D.W. Brown and L. Jin. 2006. Genetic variability of measles virus in acute and persistent infections. Infect. Genet. Evol. Jul 6(4): 269-276. Epub 2005 Sep 19.

Kremer J.R., K.E. Brown, L. Jin, S. Santibanez, S.V. Shulga, Y. Aboudy, I.V. Demchyshyna, S. Djemileva, J.E. Echevarria, D.F. Featherstone and others. 2008. High genetic diversity of measles virus, World Health Organization European Region, 2005-2006. Emerg. Infect. Dis. 14(1): 107-114. 
Makówka A., W. Gut and B. Litwińska. 2007. Measles elimination programme on the world and Poland. (in Polish) Przegl. Epidemiol. 61(1): 135-142.

Mankertz A., Z. Mihneva, H. Gold, S. Baumgarte, A. Baillot, R. Helble, H. Roggendorf, G. Bosevska, J. Nedeljkovic, A. Makowka and others. 2011. Spread of measles virus D4-Hamburg, Europe, 2008-2011. Emerg. Infect Dis. 17(8): 1396-401.

Marinova L., M. Muscat, Z. Mihneva and M. Kojouharova. 2009. An update on an ongoing measles outbreak in Bulgaria, AprilNovember 2009. Euro. Surveill. Dec 17; 14(50).pii: 19442.

Melidou A., G. Gioula, V. Pogka, M. Exindari, A. Moutoussi, D. Sgouras, K. Papadakos, D. Chatzidimitriou, D. Karabaxoglou, A. Mentis and others. 2011. Molecular and phylogenetic analysis of Greek measles 2010 strains. Epidemiol. Infect. 31: 1-7.

Muscat M. 2011. Who gets measles in Europe? J. Infect. Dis. 204 Suppl 1: S353-365.

Necula G., M. Lazar, A. Stanescu, A. Pistol, S. Santibanez, A. Mankertz and E. Lupulescu. 2013. Transmission and molecular characterisation of wild measles virus in Romania, 2008 to 2012. Euro. Surveill. 12; 18(50): 20658.

Riddell M.A., J.S. Rota and P.A. Rota. 2005. Review of the temporal and geographical distribution of measles virus genotypes in the prevaccine and postvaccine eras. Virol. J. 22, 2: 87.

Rogalska J., S. Santibanez, A. Mankertz, A. Makówka, L. Szenborn and P. Stefanoff. 2010. Spotlight on measles 2010: An epidemiological overview of measles outbreaks in Poland in relation to the measles elimination goal. Euro Surveill. Apr29; 15(17) pii.i: 19549 .
Rozanov M., U. Plikat, C. Chappey, A. Kochergin and T. Tatusova. 2004. A web-based genotyping resource for viral sequences. Nucleic Acids Res. 1; 32 (Web Server issue): W654-9.

Santibanez S., A. Tischer, A. Heider, A. Siedler and H. Hengel. 2002. Rapid replacement of endemic measles virus genotypes. J. Gen. Virol. 83(Pt 11): 2699-2708.

Shakya A.K., V. Shukla, H.S. Maan and T.N. Dhole. 2012. Identification of different lineages of measles virus strains circulating in Uttar Pradesh, North India. Virol. J. 9: 237.

Spika J.S., C. Aidyralieva, L. Mukharskaya, N.N. Kostyuchenko, M. Mulders, G. Lipskaya and N. Emiroglu. 2006. Measles outbreak in the Ukraine, 2005-2006. Euro. Surveill. 11(3): E060309.1.

Steffens I., R. Martin and P.L. Lopalco. 2010. Spotlight on measles 2010: Measles elimination in Europe - a new commitment to meet the goal by 2015. Euro. Surveill. Volume 15, Issue 50.

Tischer A., S. Santibanez, A. Siedler, A. Heider and H. Hengel. 2004. Laboratory investigations are indispensable to monitor the progress of measles elimination-results of the German Measles Sentinel 1999-2003. J. Clin. Virol. 3: 165-178.

Velicko I., L.L. Müller, R. Pebody, B. Gergonne, C. Aidyralieva, N. Kostiuchenko and J.S. Spika. 2008. Nationwide measles epidemic in Ukraine: the effect of low vaccine effectiveness. Vaccine 2008 Dec 9; 26(52): 6980-5. doi: 10.1016/j.vaccine.2008.09.012. Epub Sep 19.

WHO. 2012a. Measles virus nomenclature update: 2012. Wkly Epidemiol. Rec. Mar 2, 87(9): 73-78.

WHO. 2012b. Library Cataloguing-in-Publication Data. Global measles and rubella strategic plan: 2012-2020. 
